\title{
Use of Washington State newspapers for submersion injury surveillance
}

\author{
J Baullinger, L Quan, E Bennett, P Cummings, K Williams
}

University of Washington School of Medicine

$\mathrm{J}$ Baullinger

Department of Pediatrics, University of Washington School of Medicine,

Children's Hospital and Regional Medical Center

L Quan

Children's Hospital and Regional Medical Center

E Bennett

Department of Epidemiology, School of Public Health \& Community Medicine, University of Washington

P Cummings

Washington State Department of Health, Emergency Medical and Trauma

Prevention

$\mathrm{K}$ Williams

Correspondence to: Dr Linda Quan, Emergency Services CH04, Children's Hospital and Regional Medical Center, Box C5371, 4800 Sand Point Way NE, Seattle, WA 98105, USA

lquan@chmc.org

\begin{abstract}
Objectives-To evaluate the usefulness of newspapers as a surveillance tool for submersion injury, the proportion of submersion events and important details reported in Washington State newspapers was determined. It was also determined whether a letter sent to newspaper editors to encourage reporting changed the proportion and content of reported submersion events.

Methods-Newspaper articles regarding submersion were collected from 225 Washington newspapers from June 1993 through September 1998. Newspaper articles were linked to computerized state death and hospital records. Reporting during periods before and after a letter was sent encouraging more newspaper articles on submersion injury and preventative factors was compared.

Results-A total of 1874 submersion victims were identified in the three data sources. Of the 983 victims who had a death certificate, $52 \%$ were reported in at least one news article. Of the 471 persons in hospital discharge data, $25 \%$ were reported in a newspaper. Reporting of pediatric victims who died increased from $63 \%$ to $79 \%(p=0.008)$; reporting of hospitalized persons increased from $23 \%$ to $27 \%$ $(p=0.3)$. There were increases in reporting of swimming ability ( $7 \%$ to $15 \%, \mathrm{p}<0.001)$, supervision $(82 \%$ to $91 \%, p<0.001)$, and alcohol use ( $7 \%$ to $24 \%, \mathrm{p}<0.001)$. Reporting of life vest use decreased (35\% to $23 \%$, $\mathbf{p}<0.001$ ).

Conclusions-Newspapers failed to report about one half of fatal submersions and three quarters of submersions that resulted in a hospitalization. An effort to improve reporting was associated with an increase in the proportion of pediatric drownings that were reported, but a consistent improvement in content was found. The usefulness of newspaper articles as a surveillance tool may be limited. (Injury Prevention 2001;7:339-342)
\end{abstract}

Keywords: drowning; immersion; surveillance

Newspaper articles have been suggested for use as an injury surveillance tool. ${ }^{12}$ Most injury surveillance of fatal and non-fatal injuries uses computerized hospital databases, death certificate files, or medical examiner records. However, newspaper articles reporting injuries may provide details about injury circumstances and causes that are not available in other datasets.
One study reported that North Carolina newspapers covered $78 \%$ of submersions of children younger than 19 years and provided more detailed information, such as the body of water and supervision of the children, than medical examiner records. ${ }^{3}$ On the other hand, another study found that newspapers were deficient in providing prevention information when describing unintentional injury events. ${ }^{4}$

A statewide pediatric drowning prevention project was conducted in Washington State during June 1993 through September 1998. Project organizers hoped newspapers could help the program identify fatal and non-fatal submersion victims in a more timely manner than death certificates. The project encouraged newspaper editors to report submersion injuries and provide details about the circumstances, particularly among children.

The primary objective of this study was to evaluate the usefulness of newspapers as a surveillance tool. We sought to determine what proportion of submersion events were reported in Washington State newspapers and how often important details were reported. Our second objective was to determine if the prevention project's letter to newspaper editors changed the reporting of submersion events.

\section{Methods}

INTERVENTION

In December 1995, the Washington State Drowning Prevention Project sent a letter to the news editors of 225 Washington State newspapers. Newspaper staff were urged to report submersions, especially events involving children and teenagers. They were also encouraged to report information related to prevention, such as supervision, life vest use, and alcohol use. The letter included the names and telephone numbers of local and regional drowning prevention coalition coordinators willing to work with newspaper staff.

\section{NEWSPAPER ARTICLES}

Allen's Press Clipping Bureau of Seattle, Washington, a commercial newsclipping service, reviewed 225 daily, weekly, and neighborhood newspapers in Washington from June 1993 through September 1998. A research assistant reviewed newspaper articles pertaining to fatal and non-fatal submersion injuries and drowning prevention information.

The following variables were extracted from articles: victim's name, age, gender, date of submersion, date of death, county of residence, county of submersion, pre-submersion activity, swimming ability, supervision at the time of injury, life vest use, and alcohol use. 
Newspaper data were subdivided into two age groups: pediatric $(0-19$ years) and adult $(\geqslant 20$ years). We limited assessment of life vest use to the pre-submersion activities of boating and swimming. When multiple articles reported on the same submersion victim, the information was pooled.

DEATH CERTIFICATE DATA

Computerized files of Washington State death certificate data, corresponding to the same time period as the newspaper articles, were searched to extract records with an International Classification of Diseases, Ninth Revision (ICD-9) code of 994.1 or any ICD-9 E code related to submersion: $910.0-910.9,830.0$ $830.9,832.0-832.9,832.0-832.9,883.0$, and $954.0 .^{5}$

HOSPITAL DISCHARGE DATA

All civilian hospitals in Washington State send computerized discharge records to the Department of Health. These records contain diagnosis codes and E codes based on the ICD-9, clinical modification (ICD-9-CM). We searched these files for discharge records containing either an ICD-9-CM code of 994.1 or any ICD-9-CM E code as listed above. E codes are required for all injury related discharges in Washington.

DATA LINKAGE

First, hospital and death records were linked. Death records contain a full name and birth date, while hospital discharge records contain only the first two letters of both the first and last names and the birth date. When a discharge record and death record were identical in regard to all four letters and the birth date, we considered this to be a correct match. For all hospital discharge records which did not match, but were coded as dead at discharge, we searched the death files for any records with a similar date of death. We identified nine additional matches: in two cases the hospital record used a fictitious set of name characters or fictitious birth date and in seven cases the hospital record had an obvious error in either the name characters or birth date.

Linkage of newspaper articles to the combined file of hospital and death records was done using deterministic methods. First, we tried to link on names, which were often not available in the newspaper article and only partially available in hospital data. Furthermore, we often found records that matched regarding location, date, age, and sex, but had substantial differences in the name as reported in the newspaper and the death files. This was a common problem for hyphenated Hispanic last names. For each newspaper record, we also searched the death and hospital records for any victim with a date of death or injury that preceded or followed the newspaper date by two months. Among these victims, we looked for possible matches based upon age, sex, county of residence, county of death, or county of injury.

If a newspaper reported a death due to drowning, the record might not link to a

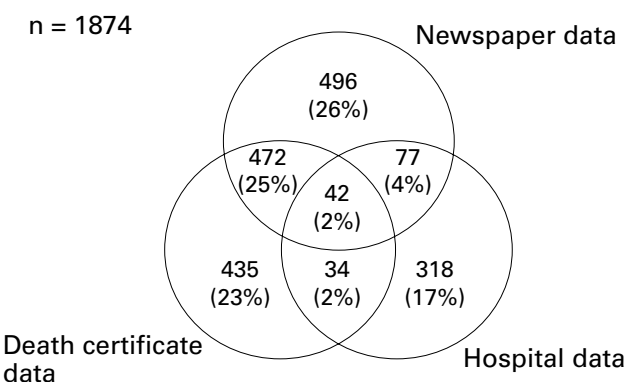

Figure 1 Venn diagram showing the distribution of study submersion victims by source of data.

Washington death certificate for the following reasons: (1) the victim really did not die; (2) the victim died but the death certificate had no code related to drowning; and (3) the victim died in Washington but was not a Washington state resident.

\section{STATISTICAL ANALYSIS}

Proportions were compared using $\chi^{2}$ tests. To assess whether differences in proportions over time differed by age group, we used $\mathrm{p}$ values from likelihood ratio tests for interaction terms in logistic regression. ${ }^{6}$ Drowning prevention and environmental risk factors, such as life vest use and type of boat used, were present only in newspaper articles, thus frequency over specific time periods was reported.

\section{Results}

NEWSPAPER COVERAGE

During the study period, we found information regarding 1874 submersion victims (fig 1 ). Of these, 496 were reported only in a newspaper article, 318 appeared only in hospital data, and 435 were found only in death certificate data. An additional 472 were in both newspaper and death certificate data, 77 in newspaper and hospital data, and 34 in hospital and death certificate data. Finally, 42 victims were found in all three data sources.

We found 1622 newspaper articles regarding 1087 submersion victims. Of the 471 submersion victims in hospital discharge data, only $119(25 \%)$ were reported in a newspaper (table 1). Among the 983 submersion victims who had a death certificate during the study interval, $514(52 \%)$ were reported in a newspaper article (table 1).

Table 1 Cross classification of submersion victims in Washington State newspapers, death certificate files, and computerized hospital records, 1993-98; values are number $(\%)$

Victims reported in newspapers

\begin{tabular}{llcc}
\hline & \multicolumn{3}{c}{ Victims in death files } \\
& Yes & No & Total \\
Yes & $514(52)$ & $573(64)$ & $1087(58)$ \\
No & $469(48)$ & $318(36)$ & $787(42)$ \\
Total & $983(100)$ & $891(100)$ & $1874(100)$ \\
& \multicolumn{3}{c}{ Victims in hospital data } \\
& Yes & No & Total \\
Yes & $119(25)$ & $968(69)$ & $1087(58)$ \\
No & $352(75)$ & $435(31)$ & $787(42)$ \\
Total & $471(100)$ & $1403(100)$ & $1874(100)$ \\
\hline
\end{tabular}


Table 2 Cross classification of fatality status for submersion victims in Washington State newspapers, death certificate files, and computerized hospital records, 1993-98; values are number (\%)

\begin{tabular}{llcc}
\hline $\begin{array}{l}\text { Deaths reported in } \\
\text { newwspapers }\end{array}$ & \multicolumn{4}{c}{ Victims in death files } \\
& \multicolumn{4}{c}{ To } & Total \\
& Yes & $177(20)$ & $667(36)$ \\
Yes & $490(50)$ & $714(80)$ & $1207(64)$ \\
No & $493(50)$ & $891(100)$ & $1874(100)$ \\
Total & $983(100)$ & \multicolumn{4}{c}{ Victims in hospital data } \\
& Yes & No & Total \\
& $30(39)$ & $637(35)$ & $667(36)$ \\
Yes & $47(61)$ & $1160(65)$ & $1207(64)$ \\
No & $77(100)$ & $1797(100)$ & $1874(100)$ \\
Total & \multicolumn{4}{c}{} \\
\hline
\end{tabular}

Table 3 Reporting in newspapers of submersion victims that appeared in Washington State death certificate files and computerized hospital data before (1993-95) and after (1996-98) a letter was sent urging newspaper staff to report submersion episodes; values are number (\%)

\begin{tabular}{lccc}
$\begin{array}{l}\text { Victims reported } \\
\text { in newspapers }\end{array}$ \\
\hline \multicolumn{4}{c}{ Victims in death files } \\
& $1993-95$ & $1996-98$ & Total \\
Yes & $240(49)$ & $274(56)$ & $514(52)$ \\
No & $251(51)$ & $218(44)$ & $469(48)$ \\
Total & $491(100)$ & $492(100)$ & $983(100)$ \\
& \multicolumn{4}{c}{ Victims in hospital data } \\
Yes & $1993-95$ & $1996-98$ & Total \\
No & $50(23)$ & $69(27)$ & $119(25)$ \\
Total & $168(77)$ & $184(73)$ & $352(75)$ \\
& $218(100)$ & $253(100)$ & $471(100)$ \\
\hline
\end{tabular}

Table 4 Proportion of submersion victims who were in death certificate files and were reported in newspapers, by age and time period

\begin{tabular}{lrrl}
\hline Age (years) & \multicolumn{1}{c}{$1993-95$} & \multicolumn{1}{c}{$1996-98$} & $p$ Value \\
\hline $0-19$ & $70 / 112(63)$ & $88 / 112(79)$ & 0.008 \\
$20-93$ & $170 / 377(45)$ & $186 / 380(49)$ & 0.3 \\
\hline
\end{tabular}

Of the 983 victims in death certificate files, $490(50 \%)$ were reported in a newspaper article to have died (table 2). The proportion of those with a death certificate who had a newspaper article was greater for children younger than 20 years than for adults: $70 \%$ and $47 \%$ respectively $(\mathrm{p}<0.001)$. Of the 667 persons reported as dead in a newspaper article, $177(27 \%)$ could not be linked to a death certificate (table 2).

THE IMPACT OF INTERVENTION

The Drowning Prevention Program letter was associated with a significant increase in the proportion of submersion victims reported in newspapers (tables 3 and 4). The increase primarily occurred in reporting of pediatric and fatal submersions. Comparing 1993-95 with 1996-98, the proportion of persons in death certificate data who had a newspaper article increased from $49 \%$ to $56 \%(\mathrm{p}=0.03)$. Among children younger than 20 years, the increase was from $63 \%$ to $79 \%(\mathrm{p}=0.008)$, while among adults, 20 years and older, the increase was from $45 \%$ to $49 \%(\mathrm{p}=0.3)$. The increase in the proportion reported was modestly greater for children compared with adults: $\mathrm{p}=$ 0.06 for a test of homogeneity. The proportion of hospitalized patients reported in newspapers increased from $23 \%$ to $27 \%(\mathrm{p}=0.3)$.

For 1993-1995 and 1996-1998, nearly $100 \%$ of newspaper articles described county
Table 5 Proportion (\%) of submersion victims for which various characteristics were reported in newspapers before (1993-95) and after (1996-98) a letter was sent urging newspaper staff to report more detail about submersion events

\begin{tabular}{lccc}
\hline Descriptive characteristics & $\begin{array}{c}1993-95 \\
(n=384)\end{array}$ & $\begin{array}{l}1996-98 \\
(n=703)\end{array}$ & p Value \\
\hline County of residence & 100 & 100 & 0.7 \\
County of submersion & 100 & 100 & 1.0 \\
Pre-submersion activity & 100 & 100 & 1.0 \\
Swimming ability & 7 & 16 & $<0.001$ \\
Supervision & 82 & 91 & $<0.001$ \\
Life vest use & 35 & 23 & $<0.001$ \\
Alcohol use & 7 & 24 & $<0.001$ \\
Type of water craft & 100 & 98 & 0.004 \\
\hline & & &
\end{tabular}
and boating activities.

Table 6 Proportion (\%) of submersion victims for which various characteristics were reported by Washington State newspapers. Data subdivided by age and according to whether the reporting was before (1993-95) or after (1996-98) a letter that urged newspapers to report more detail about submersions

\begin{tabular}{llll}
\hline Characteristics & $1993-95$ & $1996-98$ & p Value \\
\hline Age 0-19 years & $(\mathrm{n}=137)$ & $(\mathrm{n}=268)$ & \\
Swimming ability & 12 & 24 & 0.005 \\
Supervision & 62 & 79 & $<0.001$ \\
Life vest use & 34 & 11 & $<0.001$ \\
Alcohol use & 3 & 47 & $<0.001$ \\
Age 20-93 years & $(\mathrm{n}=230)$ & $(\mathrm{n}=350)$ & \\
$\quad$ Swimming ability & 4 & 11 & 0.001 \\
Supervision & 97 & 98 & 0.2 \\
Life vest use & 37 & 30 & 0.1 \\
Alcohol use & 8 & 11 & 0.3 \\
\hline
\end{tabular}

^Comparisons regarding life vest use were limited to swimming and boating activities.

of residence, county of submersion, presubmersion activity, and type of watercraft involved (table 5). The proportion of reports with information about swimming ability and alcohol use showed modest increases that were statistically significant but remained low. The proportion of reports reporting life vest use significantly decreased over time.

Following the letter to the editor, some characteristics of the incident and victim were more often reported for children compared to adults (table 6). Reporting of children and adults' swimming ability increased; however, the change was not statistically different between the two age groups $(p=0.5)$. Reporting of alcohol use increased greatly among children, changing from $3 \%$ to $47 \%$ of newspaper reports. This change was statistically different from the small change seen among adults; homogeneity test, $p<0.001$. Only reporting of life vest use decreased more among children: homogeneity test of results for children compared with adults, $\mathrm{p}=0.001$.

\section{Discussion}

During 1993 through 1998, Washington State newspapers reported only one half of the deaths and one fourth of the hospitalizations related to submersion. However, they provided information about pre-submersion activity, supervision, and type of watercraft for most victims, as Rainey and Runyan noted. ${ }^{3}$ This information is not usually available in death certificate data. However, key information for prevention, including alcohol use, life vest use or swimming ability, was not usually reported. 
In general, newspaper reporting was better for pediatric drownings. We found that $70 \%$ of children who drowned were reported in newspaper articles. This is similar to Rainey and Runyan finding newspaper articles for $78 \%$ of 58 drownings among children. ${ }^{3}$ After we sent a letter to newspaper editors encouraging more complete reporting of submersion episodes, the reporting of deaths increased significantly, especially for children. As the letter and the drowning prevention project were aimed specifically at children, the differential increase offers some support for the view that the change was caused by the letter. In addition, we noted that the number of drowning prevention related articles increased from 47 for the time period $1993-95$ to 122 articles for the time period 1996-98.

However, the content of the newspaper articles did not reach reliable levels nor did observed changes in reporting follow a consistent pattern. While reporting of swimming ability and alcohol use increased, these factors and life vest use were not reported for most victims. Reporting of supervision increased to cover over $80 \%$ of victims. On the other hand, reporting of life vest use decreased substantially, particularly among children.

Computerized death certificate and hospital data are commonly used for surveillance because of the ease of tracking useful information by a predetermined coding system. However, medical examiner records contain rich, detailed information that is not available in coded, computurized form. While we did not directly compare information from newspapers reports and medical examiner reports as Rainey did, we have previously used medical examiner data from King County, which covers about one third of Washington's population. ${ }^{7}$ Medical examiner data from King County are generally complete regarding alcohol use among those age 15 years or older and also complete regarding information about supervision and life vest use. However, attention to these factors varies among the medical examiners and coroners of the other 38 counties.

We used computerized death certificate data as the "gold standard" for identifying drowning deaths. In a prior study in King County, Washington, we obtained hospital records, death certificate computerized records, and medical examiner records to identify all deaths. ${ }^{7}$ We found that the correspondence between these regarding the fact of death due to drowning was good; computerized death certificates identified $83 \%$ of all the deaths and use of emergency medical services records, medical examiner records, and hospital chart review (not computerized records) identified $95 \%$ of the deaths.

One limitation of our study is that we did not assess the completeness of the commercial newspaper clipping service. It may be that they missed relevant articles. Nevertheless, researchers who wish to obtain data from

\section{Key points}

- Newspapers failed to report about one half of fatal submersions and three quarters of submersions that resulted in a hospitalization.

- A letter to newspaper editors was associated with a significant increase in the proportion of submersion victims reported in newspapers, primarily in reporting of pediatric and fatal submersions.

- An effort to improve reporting did not result in improved description of characteristics of the drowning.

- The usefulness of newspaper articles as a surveillance tool is limited.

newspaper articles would probably resort to such a service, possibly with similar results. Another limitation may have been in our ability to link newspaper cases with death certificate and hospital discharge files. Lastly, we contacted the newspaper editors only once; a follow up letter or call might have increased compliance.

\section{Conclusion}

Newspapers can provide timely and vivid descriptions of submersion injuries that can be useful for illustrating modifiable risks and prevention messages. However, they are an incomplete source of injury data. They reported about half of the fatalities and one fourth of hospitalized persons and the majority of pediatric drownings. Reports almost always contained information about age, gender, pre-drowning activity, supervision, and body of water. However, information regarding life vest use and alcohol use was inconsistently provided and remained low despite an effort to improve reporting. This effort was associated with an increase in the proportion of pediatric drownings that were reported. Newspapers provide a great deal of information about only some submersion injuries. Thus, the usefulness of newspaper articles as a surveillance tool is limited.

1 Fine PR, Jones CS, Wrigley JM, et al. Are newspapers a viable source for intentional injury surveillance data? South Med f 1998;91:234-42.

2 US Department of Health Education and Welfare, 1997.

3 Rainey DY, Runyan CW. Newspapers: a source for injury surveillance? Am f Public Health 1992;82:745-6.

4 Voight B, Lapidus G, Zavoski R, et al. Injury reporting in Connecticut newspapers. Inj Prev 1998;4:292-4.

5 World Health Organization. Manual of the international statistical classification of disease, injuries, and causes of death. Geneva: WHO, 1977.

6 Hosmer DW, Lemeshow S. Applied logistic regression. 2nd Ed. New York: John Wiley, 2000.

7 Cummings $\mathrm{P}$, Quan L. Trends in unintentional drowning: the role of alcohol and medical care. $f A M A$ 1999;281: 2198-202.

8 Washington State Department of Health, Center for Health Statistics, Death Certificates. Data provided in January 2001 . 